\title{
ADUBAÇÃO NITROGENADA NA SOJA INIBE A NODULAÇÃO E NÃO MELHORA O CRESCIMENTO INICIAL DAS PLANTAS
}

\author{
Alan Mario Zuffo* \\ Fábio Steiner** \\ Aécio Busch**** \\ Diego Muniz da Silva Santos****
}

RESUMO: A adubação nitrogenada pode afetar o processo de simbiose da soja com bactérias do gênero Bradyrbizobium (rizóbio), alterando a eficiência da fixação biológica de nitrogênio (FBN) e o crescimento das plantas. Portanto, objetivou-se com o trabalho avaliar o efeito de doses e épocas de aplicação de nitrogênio associada à inoculação de bactérias Bradyrbizobium japonicum, na nodulação e no crescimento inicial de duas cultivares de soja. O experimento foi realizado em condições de casa-de-vegetação, em Cassilândia (MS), Brasil, durante a safra 2016/2017. O delineamento experimental utilizado foi o de blocos casualizados, disposto em esquema fatorial $2 \times 3 \times 4$, com quatro repetições. Os tratamentos foram constituídos por duas cultivares de soja (BRS 1074 IPRO e ST 797 IPRO), três épocas de aplicação (semeadura; 30 DAE e 50 DAE) e quatro doses de nitrogênio (0, 20, 40, $\left.60 \mathrm{~kg} \mathrm{ha}^{-1} \mathrm{de} \mathrm{N}\right)$. Aos 65 dias após a emergência das plantas foram avaliados o número de nódulos, volume dos nódulos, matéria seca dos nódulos, densidade dos nódulos, matéria seca da parte aérea, matéria seca das raízes e volume radicular. A adubação nitrogenada na cultura da soja, independente da época de aplicação e do cultivar, inibe o número de nódulos, volume dos nódulos e matéria seca dos nódulos e não proporciona aumento do volume radicular, matéria seca da parte aérea e do sistema radicular.

PALAVRAS-CHAVE: Fixação biológica de nitrogênio; Glycine max L. Merrill; Nódulos.

* Doutor em Agronomia, docente visitante do Programa de Pós-graduação em Agronomia da Universidade Federal de Mato Grosso do Sul (UFMS), Chapadão do Sul (MS) Brasil. E-mail: alan_zuffo@hotmail.com

** Doutor em Agronomia, docente permanente do Programa de Pós-graduação em Agronomia da Universidade Estadual do Mato Grosso do Sul (UEMS), Cassilândia (MS) Brasil..

*** Discente de graduação em Agronomia da Universidade Estadual do Mato Grosso do Sul (UEMS), Cassilândia (MS) Brasil.

***** Discente de graduação em Agronomia da Universidade Estadual do Mato Grosso do Sul (UEMS), Cassilândia (MS) Brasil. 


\title{
NITROGEN FERTILIZATION IN SOYBEAN INHIBITS NODULATION AND FAILS TO IMPROVE PLANTS' INITIAL GROWTH
}

\begin{abstract}
Nitrogen fertilization may affect soybean symbiosis process with bacteria of the genus Bradyrbizobium (ryzobium), changing the efficiency of the biological fixation of nitrogen (BFN) and plants' growth. Current study evaluates the effect of doses and application periods of nitrogen associated with the inoculation of Bradyrbizobium japonicum bacteria, in nodulation and initial growth of two soybean cultivars. Assay was performed in a vegetation house in Cassilândia MS Brazil, during the 2016-2017 harvest. Experimental design comprised randomized blocks, within a $2 \times 3 \times 4$ factorial scheme, with four replications. Treatments consisted of two soybean cultivars (BRS 1074 IPRO and ST 797 IPRO), three application periods (seeding; 30 DAE and 50 DAE) and four N doses (0, 20, 40, $60 \mathrm{~kg} \mathrm{ha}^{-1} \mathrm{~N}$ ). After 65 days of plant emergence, the number of nodules, volume, dry matter, density, dry matter of aerial section, dry matter of roots and radicular volume were evaluated. Regardless of application period and cultivar, nitrogen fertilization in soybean culture inhibits the number, volume and dry matter of nodules. It does not increase radicular volume, dry matter of aerial section and radicular system.
\end{abstract}

KEY WORDS: Biological fixation of nitrogen; Glycine max L. Merrill; Nodules; Urea.

\section{INTRODUÇÃO}

A soja [Glycine max L. Merrill] é uma das mais importantes culturas oleaginosas do mundo. O Brasil é o segundo maior produtor de soja do mundo, superado apenas pelos Estados Unidos da América (EUA). Na safra 2016/2017, a cultura ocupou uma área de 33,7 milhões de hectares, o que totalizou uma produção de 103,6 milhões de toneladas (CONAB, 2017). A produtividade média da soja brasileira foi de $3.074 \mathrm{~kg} \mathrm{ha}^{-1}$. Os constantes avanços dos programas de melhoramento da cultura da soja, associados com a seleção de estirpes de Bradyrbizobium adaptadas às condições brasileiras, capazes de substituir totalmente o uso de fertilizantes nitrogenados, foram, sem dúvida, os principais fatores que contribuíram para a expansão da cadeia produtiva da soja no Brasil (HUNGRIA et al., 2006a; ZUFFO et al., 2015).

A adoção de práticas agrícolas sustentáveis que otimizam a fixação biológica de nitrogênio (FBN) e o rendimento de grãos da cultura são de extrema importância 
para o agronegócio da soja no Brasil. De acordo com Zuffo et al. (2016), o uso de inoculantes contendo estirpes de Bradyrhizobium sp. resultou na economia de US\$ 8,7 bilhões, na safra 2015/16, em fertilizantes nitrogenados. A quantidade de nitrogênio atmosférico $\left(\mathrm{N}_{2}\right)$ fixado através da simbiose da soja com bactérias do gênero Bradyrbizobium (rizóbio) pode chegar a até $300 \mathrm{~kg} \mathrm{ha}^{-1}$ de N, o que pode representar até $94 \%$ do $\mathrm{N}$ total acumulado pelas plantas (HUNGRIA et al., 2006a).

Nas condições tropicais brasileiras, o processo de FBN através da simbiose Bradyrbizobium-soja pode fornecer todo o $\mathrm{N}$ que a soja necessita, desde que respeitados os procedimentos para uma adequada nodulação. Atualmente, a recomendação para o cultivo de soja é a utilização de inoculante sem a suplementação com fertilizante nitrogenado, ou de até $20 \mathrm{~kg} \mathrm{ha}^{-1}$ na semeadura (EMBRAPA, 2011). No entanto, a adubação nitrogenada para a cultura da soja é tema muito polêmico dentro da comunidade científica (SEDIYAMA, 2016).

Alguns estudos reportaram que o uso de fertilizantes nitrogenados, em doses superiores a $20 \mathrm{~kg} \mathrm{ha}^{-1}$ de $\mathrm{N}$, pode reduzir a nodulação e a eficiência da FBN, e não melhora o desempenho produtivo da cultura (HUNGRIA et al., 2006b; ARATANI et al. 2008; KASCHUK et al., 2016). Por outro lado, pesquisas realizadas demonstraram que adubação nitrogenada pode melhorar o desenvolvimento e a produtividade da cultura da soja (BARRANQUEIRO; DALCHIAVON, 2017; MORENO et al., 2018). Araújo e Carvalho (2006) comentaram que em algumas situações, como em áreas de primeiro cultivo de soja, onde não existem populações de rizóbio no solo, a aplicação de baixas doses de $\mathrm{N}$ na semeadura (20 a $30 \mathrm{~kg} \mathrm{ha}^{-1} \mathrm{de} \mathrm{N}$ ) deve ser recomendada com a finalidade de disponibilizar $\mathrm{N}$ às plantas até o início da nodulação. Portanto, tem-se disseminado, no Brasil, que a soja necessita de uma adubação nitrogenada de "arranque", para suprir uma eventual deficiência de $\mathrm{N}$ durante a fase inicial da cultura, que ainda não foi infeccionada pelas bactérias Bradyrbizobium japonicum (ALMEIDA, 2015).

Diante do exposto, o entendimento do processo de formação dos nódulos associado à aplicação suplementar de nitrogênio na cultura da soja é de extrema importância para o adequado manejo da cultura visando aumentar a eficiência da utilização de $\mathrm{N}$ e incrementar a produtividade da cultura. Objetivou-se com o trabalho avaliar o efeito de doses e épocas de aplicação de nitrogênio associada à inoculação 
de bactérias Bradyrbizobium japonicum, na nodulação e no crescimento inicial de duas cultivares de soja.

\section{MATERIAL E MÉTODOS}

\subsection{LOCALIZAÇÃO E CARACTERIZAÇÃO DA ÁREA EXPERIMENTAL}

O experimento foi realizado em condições de casa-de-vegetação na Universidade Estadual de Mato Grosso do Sul (UEMS), em Cassilândia (MS) (19006'48" de latitude Sul; 5144'03" de longitude Oeste e altitude média de $470 \mathrm{~m}$ ), no período de novembro de 2016 a janeiro de 2017. O clima da região, segundo classificação de Köppen, é do tipo tropical chuvoso (Aw), com verões chuvosos e invernos secos, com precipitação média anual de $1.520 \mathrm{~mm}$ e temperatura média anual de $24,1^{\circ} \mathrm{C}$. As condições ambientais durante a condução do experimento foram monitoradas diariamente com o auxílio de uma Estação Meteorológica Automática (Cassilandia-A742), e os dados de temperatura e umidade relativa do ar coletados são mostrados na Figura 1.

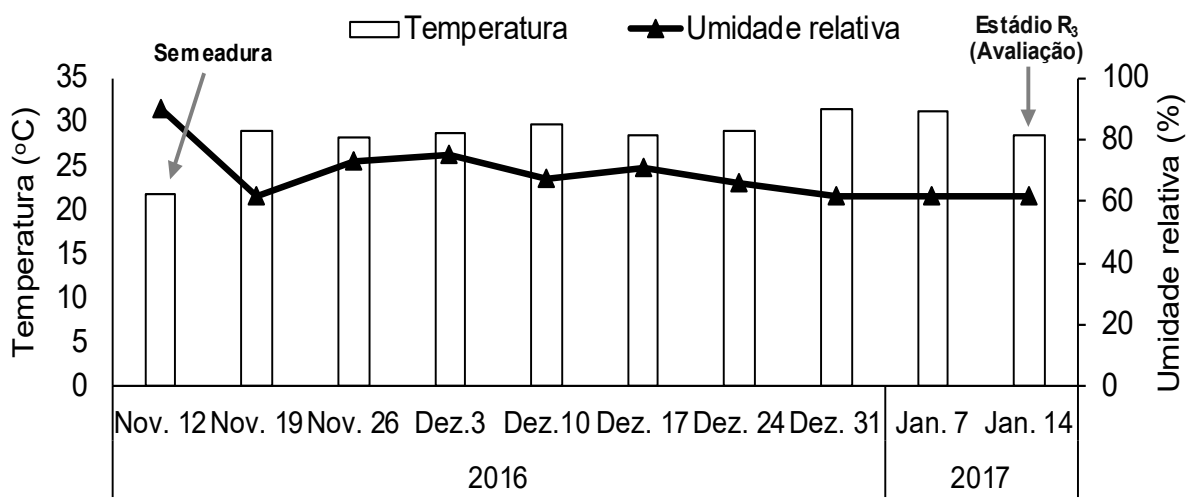

Figura 1. Temperatura média $\left({ }^{\circ} \mathrm{C}\right)$ e umidade relativa do ar (\%) dentro da casa-de-vegetação durante o período de condução do experimento com cultivo de soja.

O solo utilizado no experimento foi um Neossolo Quartzarênico de textura arenosa (95 $\mathrm{g} \mathrm{kg}^{-1}$ de argila), coletado na camada superficial de 0,0-0,20 m em uma área de pastagem sem histórico de cultivo de soja. A escolha da área de coleta do 
solo foi em razão da ausência de histórico de cultivo de soja. Solo de áreas de primeiro cultivo de soja pode ser considerado ideal para testar a interação entre a simbiose Bradyrbizobium-soja e a aplicação de nitrogênio. Após a coleta, o solo foi peneirado em malha de $4 \mathrm{~mm}$ e caracterizado quanto as suas características químicas seguindo as indicações da Embrapa (2009). As principais características químicas do solo estão apresentadas na Tabela 1 .

Tabela 1. Principais propriedades químicas do solo utilizado no experimento

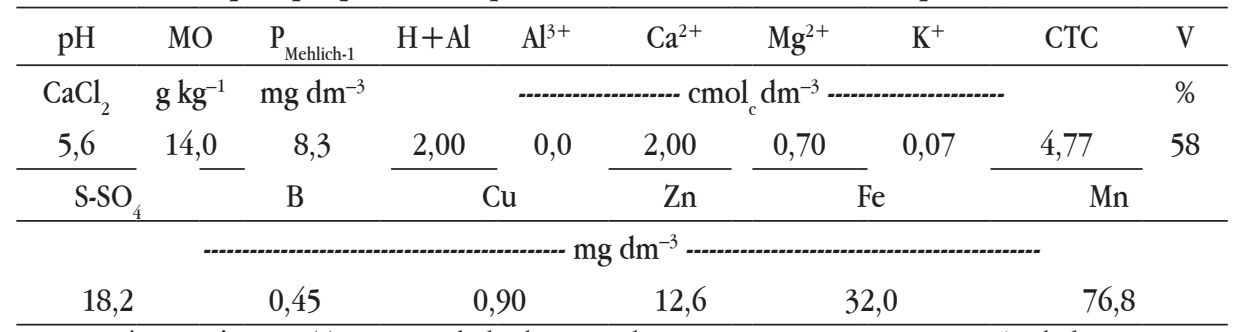

MO: Matéria orgânica. CTC: Capacidade de troca de cations a pH 7,0. V: Saturação de bases.

A correção da acidez do solo foi realizada com a aplicação de $675 \mathrm{mg}$ de calcário por $\mathrm{dm}^{3}$ de solo (CaO: 38\%; MgO: 11\%; PRNT: 85\%; PN: 62\%), visando elevar a saturação por base do solo a $70 \%$. Após a calagem, o solo foi homogeneizado, umedecido e mantido incubado por 30 dias. Decorrido esse período, o solo foi acondicionado em vasos de polietileno com capacidade para $8,0 \mathrm{dm}^{3}$ e, então, fertilizado com $400 \mathrm{mg} \mathrm{dm}^{-3}$ de $\mathrm{P}$ (superfosfato simples) e $125 \mathrm{mg} \mathrm{dm}^{-3}$ de $\mathrm{K}$ (cloreto de potássio). Aos 20 dias após a emergência (DAE) foram, novamente, aplicados 125 $\mathrm{mg} \mathrm{dm}{ }^{-3}$ de $\mathrm{K}$ (cloreto de potássio) em cobertura.

\subsection{DELINEAMENTO EXPERIMENTAL E TRATAMENTOS}

O delineamento experimental utilizado foi o de blocos casualizados, disposto em esquema fatorial $2 \times 3 \times 4$, com quatro repetições. Os tratamentos foram constituídos por duas cultivares de soja (BRS 1074 IPRO - hábito de crescimento indeterminado, ciclo de 108 a 114 dias, grupo de maturação 7,4 e ST 797 IPRO hábito de crescimento indeterminado, ciclo de 120 a 130 dias, grupo de maturação 7,9), três épocas de aplicação de $\mathrm{N}$ (semeadura; 30 DAE e 50 DAE) e quatro doses de nitrogênio $\left(0,20,40,60 \mathrm{~kg} \mathrm{ha}^{-1} \mathrm{de} \mathrm{N}\right)$. A fonte de $\mathrm{N}$ utilizada foi a ureia ( $45 \% \mathrm{de} \mathrm{N}$ ), e as aplicações foram realizadas na forma de solução com $20 \mathrm{~mL}$ por vaso. 


\subsection{IMPLANTAÇÃO E CONDUÇÃO DO EXPERIMENTO}

Sementes de soja previamente tratadas com piraclostrobina + tiofanato metílico + fipronil (Standak Top ${ }^{\circledR}$ ) na dose de $2 \mathrm{~mL} \mathrm{p.c.} \mathrm{kg}^{-1}$ de semente foram inoculadas com Bradyrbizobium japonicum, utilizou-se o inoculante comercial líquido Simbiose Nod Soja ${ }^{\circledR}$ (Simbiose: Agrotecnologia Biológica) contendo as estirpes SEMIA 5079 e SEMIA 5080 (concentração mínima de 7,2 x $10^{9}$ células viáveis por $\mathrm{mL}$ ), na dose de $150 \mathrm{~mL}$ para $50 \mathrm{~kg}$ de sementes. A quantidade de inoculante utilizada foi dissolvida em uma solução contendo $2 \mathrm{~mL}$ p.c. $\mathrm{kg}^{-1}$ de semente de aditivo para inoculante Protege $^{\circledR}$ TS (Total Biotecnologia) e, então, ambos os produtos (inoculante + aditivo) foram aplicados nas sementes. $\mathrm{O}$ aditivo para inoculante é constituído de metabólitos ativos de bactérias, complexo de açúcares e biopolímeros encapsulantes e tem a finalidade de melhorar a proteção e a viabilidade das bactérias sobre as sementes. Para potencializar a nodulação da soja, as sementes também receberam a aplicação de micronutrientes, especialmente, de molibdênio. A fonte utilizada foi o fertilizante comercial para sementes Nódulus ${ }^{\circledR}$ Premium 125 (Biosoja) contendo: Mo, $10 \%$; Co, $1 \%$; S, 1\%; Ca, 1\%; Fe, 0,2\%.

A semeadura foi realizada distribuindo-se 10 sementes por vaso na profundidade de 1-2 cm, e aos dez dias após a semeadura, realizou-se o desbaste deixando-se apenas duas plantas por vaso. O teor de água do solo foi mantido próximo da capacidade de retenção de água com irrigações diárias.

\subsection{MENSURAÇÃO DAS AVALIAÇÕES}

Aos 65 DAE (Estádio $R_{3}$ - início da formação do legume) foram avaliadas: número de nódulos - obtido pela contagem do número de nódulos presentes nas raízes; volume dos nódulos - foi determinado pelo método de deslocamento de água, utilizando uma proveta graduada de 0,1 mililitros $(\mathrm{mL})$ e capacidade de $10 \mathrm{~mL}$. Em seguida, os nódulos foram destacados e colocados em estufa por 48 horas a 65 ${ }^{\circ} \mathrm{C}$ com pesagem do material seco em balança analítica com precisão de $0,0001 \mathrm{~g}$ e, então, calculado a razão entre a massa de matéria seca dos nódulos e o número de nódulos para obter-se a massa de matéria seca média por nódulo e a densidade dos nódulos por meio da divisão da massa seca e o volume dos nódulos.

Para a mensuração da massa de matéria seca da parte aérea e das raízes, as 
plantas foram seccionadas em parte aérea e raízes e, em seguida, acondicionadas em sacos de papel, colocadas para secar em estufa a $65{ }^{\circ} \mathrm{C}$ por 72 horas e, posteriormente, pesadas em balança analítica com precisão de $0,0001 \mathrm{~g}$, sendo os resultados expressos em $\mathrm{g} /$ planta. $\mathrm{O}$ volume radicular foi determinado pelo método de deslocamento de água, utilizando uma proveta de $100 \mathrm{~mL}$ graduada em mililitros (mL), portanto, com precisão de $\pm 1,0 \mathrm{~cm}^{3}$.

\subsection{ANÁLISES ESTATÍSTICAS}

Os dados experimentais foram submetidos aos testes de verificação das pressuposições de normalidade e homogeneidade. Não foram atendidas tais pressuposições em nenhuma das variáveis avaliadas. Sendo assim, os dados foram previamente transformados com o uso da função raiz quarta $(\sqrt[4]{x})$. Após a análise dos dados transformados verificou-se o atendimento da pressuposição, no entanto, os dados foram apresentados na forma original. Os dados foram submetidos à análise de variância (ANOVA), e quando significativas, as médias foram comparadas pelo teste LSD, ao nível de 5\% de probabilidade, utilizando-se o programa estatístico Sis$\operatorname{var}^{\circledR}$ versão 5.3 para Windows (Software de Análises Estatísticas, UFLA, Lavras (MG), BRA). Para as doses de $\mathrm{N}$ foram utilizadas a análise de regressão e as equações significativas com os maiores coeficientes de determinação (teste $\mathrm{F}, \mathrm{p}<0,05$ ) foram ajustadas. As análises de regressão foram realizadas usando o software SigmaPlot 11.0 para Windows (Systat Software, Inc., San José, CA, EUA).

\section{RESULTADOS E DISCUSSÃO}

\subsection{NODULAÇÃO DAS PLANTAS DE SOJA}

Os resultados reportaram efeitos significativos $(\mathrm{p}<0,01)$ entre as cultivares de soja $(\mathrm{C})$ para as variáveis número de nódulos, volume dos nódulos por planta massa e matéria seca dos nódulos (Tabela 2). A época de aplicação de nitrogênio (E) influenciou significativamente ( $\mathrm{p}<0,05)$ o número de nódulos por planta e a matéria seca média por nódulo (Tabela 2). As doses de $\mathrm{N}$ (D) afetaram significativamente a maioria das características relacionadas à nodulação das raízes de soja, exceto a densidade dos nódulos (Tabela 2). Os resultados da análise de variância também reportaram efeitos significativos da interação $C$ x E e C x D para a variável matéria 
seca média por nódulo. Para as demais interações não foram constatadas diferenças significativas.

Tabela 2. Análise de variância e valores médios do número de nódulos, volume dos nódulos, matéria seca dos nódulos, matéria seca média por nódulo e densidade dos nódulos, obtidas no ensaio com doses e épocas de aplicação de nitrogênio em duas cultivares de soja. Cassilândia (MS), Brasil. 2016/2017

\begin{tabular}{|c|c|c|c|c|c|}
\hline \multirow[t]{2}{*}{ Fontes de variação } & Nódulos & $\begin{array}{l}\text { Volume } \\
\text { dos nó- } \\
\text { dulos }\end{array}$ & $\begin{array}{l}\text { Matéria seca } \\
\text { dos nódulos }\end{array}$ & $\begin{array}{c}\text { Matéria } \\
\text { seca média } \\
\text { por nódulo }\end{array}$ & $\begin{array}{c}\text { Densidade } \\
\text { dos nódu- } \\
\text { los } \\
\end{array}$ \\
\hline & $\left(\mathrm{n}^{\circ}\right)$ & $\left(\mathrm{cm}^{3}\right)$ & (mg/planta) & $\begin{array}{c}\text { (mg/nódu- } \\
\text { lo) }\end{array}$ & $\mathrm{g} / \mathrm{cm}^{3}$ \\
\hline Teste F & \multicolumn{5}{|c|}{ Probabilidade $>\mathrm{F}^{1}$} \\
\hline Cultivar (C) & $<0,000$ & $<0,000$ & $<0,000$ & 0,413 & 0,512 \\
\hline Época (E) & 0,028 & 0,676 & 0,729 & 0,048 & 0,456 \\
\hline Dose (D) & $<0,000$ & $<0,000$ & $<0,000$ & 0,029 & 0,067 \\
\hline Interação $(\mathrm{C} \times \mathrm{E})$ & 0,151 & 0,881 & 0,247 & $<0,000$ & 0,121 \\
\hline Interação $(\mathrm{C} \times \mathrm{D})$ & 0,436 & 0,600 & 0,226 & 0,057 & 0,865 \\
\hline Interação (E × D) & 0,272 & 0,851 & 0,383 & 0,396 & 0,844 \\
\hline Interação $(\mathrm{C} \times \mathrm{E} \times \mathrm{D})$ & 0,784 & 0,732 & 0,925 & 0,556 & 0,898 \\
\hline CV (\%) & 12,27 & 16,07 & 13,75 & 9,05 & 10,43 \\
\hline Fatores & & & Valores méd & & \\
\hline \multicolumn{6}{|l|}{ Cultivar $^{2}$} \\
\hline BRS 1074 IPRO & $11,03 \mathrm{~b}$ & $1,20 \mathrm{a}$ & $77,09 \mathrm{~b}$ & $7,16 \mathrm{a}$ & $0,20 \mathrm{a}$ \\
\hline ST 797 IPRO & $33,46 \mathrm{a}$ & $0,43 \mathrm{~b}$ & $211,00 \mathrm{a}$ & $6,93 \mathrm{a}$ & $0,18 \mathrm{a}$ \\
\hline \multicolumn{6}{|l|}{ Época de aplicação de $\mathrm{N}^{3}$} \\
\hline Semeadura & $24,70 \mathrm{a}$ & $0,84 \mathrm{a}$ & $145,14 \mathrm{a}$ & $6,55 \mathrm{~b}$ & $0,21 \mathrm{a}$ \\
\hline $30 \mathrm{DAE}$ & $18,28 \mathrm{~b}$ & $0,79 \mathrm{a}$ & $139,84 \mathrm{a}$ & $7,98 \mathrm{a}$ & $0,19 \mathrm{a}$ \\
\hline $50 \mathrm{DAE}$ & $23,76 \mathrm{a}$ & $0,82 \mathrm{a}$ & $147,17 \mathrm{a}$ & $6,59 \mathrm{~b}$ & $0,17 \mathrm{a}$ \\
\hline
\end{tabular}

${ }^{1}$ Teste F de Fisher-Snedecor.

${ }^{2}$ Médias seguidas pela mesma letra não têm diferença, de acordo com o teste $\mathrm{F}$.

${ }^{3}$ Médias seguidas pela mesma minúscula na coluna são do mesmo grupo, de acordo com teste t (LSD) teste a 5\% de probabilidade. CV: coeficiente de variação; DAE: dias após a emergência.

Os maiores valores do número de nódulos e matéria seca dos nódulos foram verificados na cultivar de soja ST 797 IPRO; todavia, os maiores valores de volume dos nódulos por planta foram observados na cultivar BRS 1074 IPRO (Tabela 2). Este fato pode estar relacionado ao maior número de nódulos ter resultado em maior número de drenos, sendo assim, como a cultivar BRS 1074 IPRO teve menor 
número de nódulos por planta, estes nódulos se desenvolveram mais.

Para a época de semeadura, as aplicações de $\mathrm{N}$ aos $30 \mathrm{DAE}$ inibiram o número de nódulos (Tabela 2). Por outro lado, este menor número de nódulos por planta refletiu em maior matéria seca média por nódulo, devido ao menor número de dreno por planta. Cabe salientar que a época de aplicação de $\mathrm{N}$ não afetou as demais variáveis estudadas que envolvem os nódulos.

De modo geral, as aplicações de $\mathrm{N}$ resultaram em inibições no número de nódulos e volume dos nódulos (Figura 2). Inibições no número dos nódulos em função da adubação nitrogenada da soja foram constatadas por Hungria et al. (2006b). Em outro estudo, Hungria et al. (2000) constataram que a adição de $20 \mathrm{~kg}$ de $\mathrm{N} \mathrm{ha}^{-1}$ na semeadura resultou em diminuição de $14 \%$ na nodulação, avaliada aos 30 dias, e redução de produtividade de $147 \mathrm{~kg}$ de grãos ha ${ }^{-1}$.

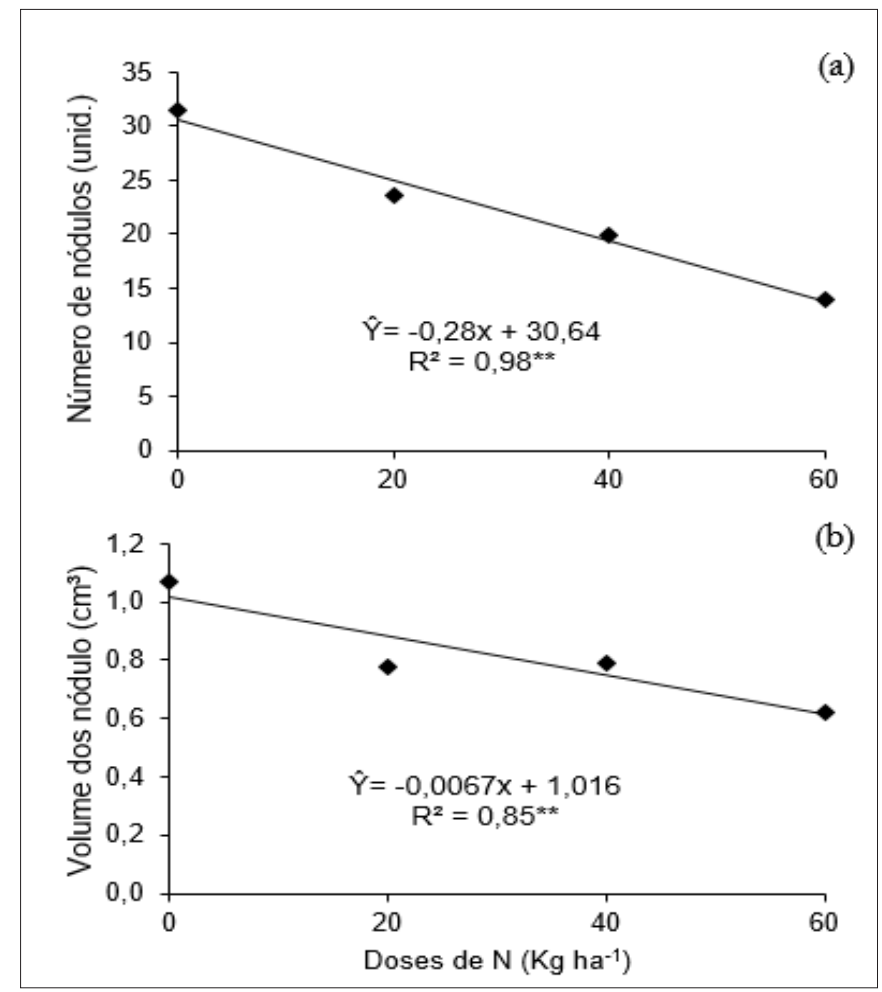

Figura 2. Número de nódulos (a) e volume dos nódulos (b) das raízes de soja em função das doses de nitrogênio. Cassilândia (MS), Brasil. 2016/2017. **: significativo a 1\% de probabilidade pelo teste $\mathrm{F}$. 
O estímulo para a infecção das bactérias Bradyrbizobium japonicum ocorre em condições de baixa disponibilidade de $\mathrm{N}$ no solo, fato este que induz o estresse necessário à produção do isoflavona para expressar o fator do gene NOD (ALMEIDA, 2015). Dessa forma, independentemente da época de aplicação, as doses de $\mathrm{N}$ culminaram na inibição da infecção das bactérias Bradyrbizobium japonicum e, consequentemente, na formação do número de nódulos por plantas ao incrementar as doses de $\mathrm{N}$.

Além do número de nódulos é essencial verificar o tamanho dos nódulos, pois é desejável nódulos com tamanho igual ou superior a 2,0 mm, que são os nódulos com maior capacidade de fixação de $\mathrm{N}_{2}$ (HUNGRIA; CAMPO; MENDES; 2001). Neste sentido, verificou-se que as doses $\mathrm{N}$ afetaram também o tamanho dos nódulos, constatado pelo menor volume dos nódulos (Figura $2 b$ ).

Em geral, verifica-se que houve inibição da matéria seca dos nódulos com a aplicação das doses de N (Figura 3). Todavia, houve efeito significativo apenas para a cultivar ST 797 IPRO. Tais achados corroboram aos verificados por Hungria et al. (2006b), os quais verificaram que a adubação nitrogenada inibiu a massa seca dos nódulos na cultura da soja.

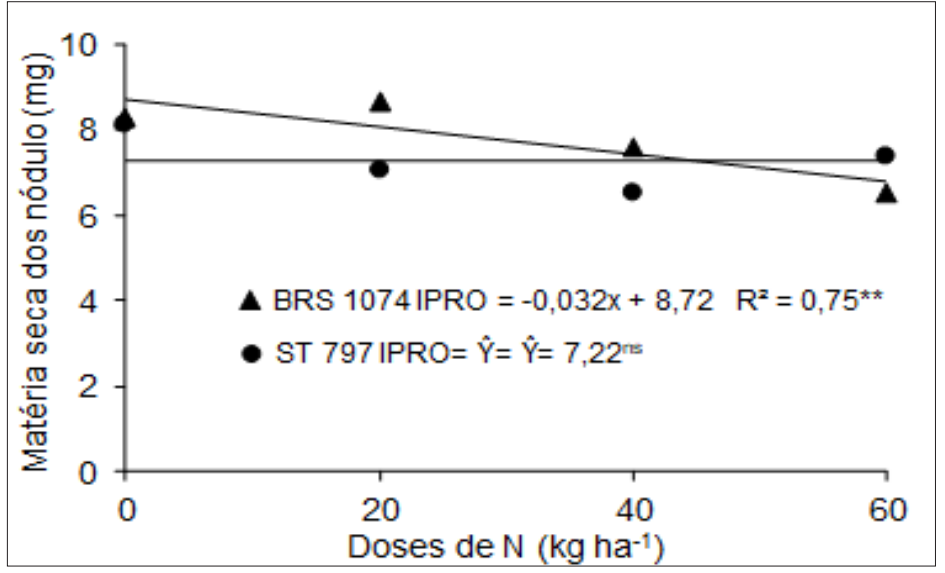

Figura 3. Massa de matéria seca dos nódulos de soja em função de cultivares e doses de N. Cassilândia (MS), Brasil. 2016/2017. **: significativo a 1\% de probabilidade pelo teste $\mathrm{F} .{ }^{\text {ns }}$ - não significativo.

As reduções dos nódulos das raízes de soja em função das doses de $\mathrm{N}$ podem estar relacionados às mudanças de translocação dos fotoassimilados nas plan- 
tas. Haja vista, que segundo Saito et al. (2014), na ausência de nitrato na planta, a maior parte dos fotoassimilados é translocada para os nódulos, em seguida, raízes primárias, e, a menor proporção, para as raízes secundárias; todavia, na presença de nitrato há uma mudança no padrão de translocação dos fotoassimilados, sendo que as raízes secundárias se tornam o principal dreno e os nódulos por sua vez recebem a menor quantidade dos fotoassimilados.

$\mathrm{Na}$ interação C x E, verificou-se que a cultivar BRS 1074 IPRO apresentou menor matéria seca de nódulo quando o $\mathrm{N}$ foi aplicado aos $50 \mathrm{DAE}$; todavia, para a cultivar ST 797 IPRO obteve inibição na matéria seca dos nódulos quando a aplicação de $\mathrm{N}$ foi realizada na semeadura (Figura 4). Portanto, fica evidente que a aplicação de $\mathrm{N}$ na semeadura inibe a matéria seca dos nódulos da cultivar ST 797 IPRO. Para Herridge e Rose (2000) o nitrato presente no solo é um fator limitante à atividade de nodulação.

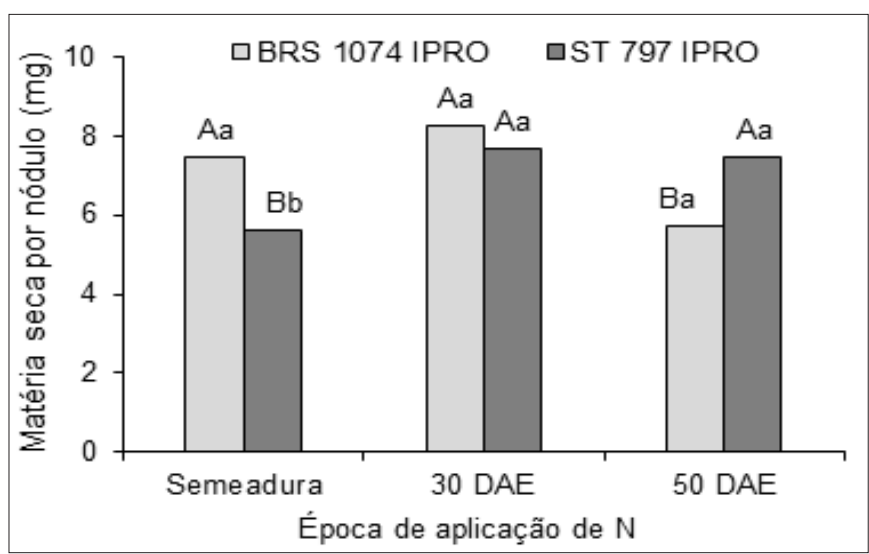

Figura 4. Massa seca por nódulo de plantas de soja em função de cultivares e épocas. Cassilândia (MS), Brasil. 2016/2017. Letras maiúscula para épocas de aplicação, e minúscula para as cultivares não diferem entre si pelo teste t (LSD) a 5\% de probabilidade. DAE - dias após a emergência.

\subsection{MATÉRIA SECA DAS PLANTAS DE SOJA}

As cultivares de soja influenciaram significativamente $(\mathrm{p}<0,01)$ a matéria seca da parte aérea, matéria seca das raízes e o volume radicular (Tabela 3). Estas variações estão relacionadas às diferenças no potencial genético, hábito de crescimento, e outros atributos de cada cultivar (SOARES et al., 2015; FELISBERTO et al., 2015). As épocas de aplicação de $\mathrm{N}$ resultaram em efeitos significativos $(\mathrm{p}<0,01)$ 
nas variáveis matéria seca das raízes e volume radicular (Tabela 3). Para os demais fatores e interações não foram constatadas diferenças significativas. Esses resultados são semelhantes aos verificados por Hungria et al. (2006b), os quais não verificaram efeito da adubação nitrogenada na matéria seca da parte aérea de plantas de soja.

Tabela 3. Análise de variância e valores médios da matéria seca da parte aérea, matéria seca das raízes e volume radicular, obtidas no ensaio de doses e épocas de aplicação de nitrogênio em duas cultivares de soja. Cassilândia (MS), Brasil. 2016/2017

\begin{tabular}{lccc}
\hline \multirow{2}{*}{ Fontes de variação } & $\begin{array}{c}\text { Matéria seca da parte } \\
\text { aérea }\end{array}$ & Matéria seca das raízes & Volume radicular \\
\cline { 2 - 4 } & $(\mathrm{g})$ & $(\mathrm{g})$ & $\left(\mathrm{cm}^{3}\right)$ \\
\hline Teste F & \multicolumn{3}{c}{ Probabilidade $>\mathrm{F}^{1}$} \\
\hline Cultivar (C) & 0,000 & $<0,000$ & $<0,000$ \\
Época (E) & 0,093 & $<0,000$ & $<0,000$ \\
Dose (D) & 0,954 & 0,492 & 0,317 \\
Interação (C x E) & 0,479 & 0,806 & 0,590 \\
Interação (C x D) & 0,989 & 0,684 & 0,923 \\
Interação (E x D) & 0,451 & 0,471 & 0,287 \\
Interação (C x E x D) & 9,00 & 0,437 & 0,614 \\
CV (\%) & & 7,53 & 5,57 \\
\hline Fatores & & & \\
\hline Cultivar & & & \\
BRS 1074 IPRO & $4,91 \mathrm{~b}$ & $1,31 \mathrm{~b}$ & $16,60 \mathrm{~b}$ \\
ST 797 IPRO & $6,84 \mathrm{a}$ & $2,17 \mathrm{a}$ & $28,27 \mathrm{a}$ \\
Época de aplicação de N & & & \\
Semeadura & $6,21 \mathrm{a}$ & $1,79 \mathrm{a}$ & $22,95 \mathrm{a}$ \\
30 DAE & $6,15 \mathrm{a}$ & $1,97 \mathrm{a}$ & $24,38 \mathrm{a}$ \\
50 DAE & $5,26 \mathrm{a}$ & $1,46 \mathrm{~b}$ & $19,97 \mathrm{~b}$ \\
\hline
\end{tabular}

${ }_{1}^{1}$ Teste F de Fisher-Snedecor.

${ }^{2}$ Médias seguidas pela mesma letra não diferem entre si pelo teste $\mathrm{F}$ de Fisher-Snedecor.

${ }^{3}$ Médias seguidas pela mesma minúscula na coluna não diferem entre si pelo teste t (LSD) teste a 5\% de probabilidade. CV: coeficiente de variação; DAE - dias após a emergência.

As maiores médias de matéria seca da parte aérea, matéria seca das raízes e volume radicular foram observados no cultivar ST 797 IPRO (Tabela 3). Estes resultados possivelmente estão relacionados ao fato deste cultivar ter apresentado maior 
número de nódulo e matéria seca dos nódulos, o que resultou na maior eficiência do processo de fixação biológica de N. Sabe-se que o N é componente responsável por várias reações nas plantas, além de fazer parte da estrutura da clorofila, de enzimas e proteínas. As clorofilas atuam na conversão da radiação luminosa em energia química, na forma de ATP (adenosina trifostato) e NADPH (nicotinamida adenina dinucleótideo fosfato reduzida) (BLANKENSHIP, 2009), sendo assim, as clorofilas estão relacionadas com a eficiência fotossintética das plantas, desde o crescimento à adaptabilidade aos diferentes ambientes. Portanto, os maiores números e massa de nódulos promoveram uma maior fixação de $\mathrm{N}$ e, consequentemente, uma maior quantidade de clorofila. Tais condições proporcionaram um aumento na taxa fotossintética na planta, na qual proporcionam ganhos na produção de fotoassimilados e, consequentemente, melhor acúmulo de matéria seca da parte aérea e das raízes (Tabela 3).

Aplicações de $\mathrm{N}$ aos 50 DAE culminaram em inibição da matéria seca das raízes e volume radicular (Tabela 3); entretanto, as doses de $\mathrm{N}$ não afetaram essas variáveis. Destaca-se ainda que apesar de ter observado reduções nas variáveis relacionadas aos nódulos quando houve aplicação de $\mathrm{N}$, percebe-se que tais efeitos não culminaram no menor crescimento das plantas. Nesse sentido, a FBN foi capaz de suprir a demanda por $\mathrm{N}$ a fim de atingir o máximo de eficiência fisiológica, pois, mesmo nos tratamentos em que foi adicionado $\mathrm{N}$ mineral não resultou em diferenças no desenvolvimento da planta.

Do ponto de vista econômico, a produção de grãos é mais importante que a fitomassa seca total. Entretanto, por exemplo, o rendimento de culturas como o milho e a soja está intimamente ligado à eficiência fotossintética na transformação da radiação solar interceptada e transformada em matéria seca (CASAROLI et al., 2007). Embora no presente estudo não tenha sido avaliada a produtividade da soja (em função da destruição das plantas para a coleta dos dados), novos trabalhos devem ser realizados a fim de testar a produtividade e os componentes de produção e se é viável economicamente a aplicação de adubação nitrogenada.

Para Embrapa (2011), recomenda-se utilizar doses de $\mathrm{N}$ menores que $20 \mathrm{~kg}$ $\mathrm{ha}^{-1}$ quando os adubos formulados que contêm $\mathrm{N}$ serem mais econômicos que os sem N. Portanto, como há efeito negativo na nodulação e não influência à produção 
de matéria seca das plantas de soja. A adubação nitrogenada na soja só deverá ser utilizada em casos em que for mais econômico ao produtor comprar um adubo formulado, em que o $\mathrm{N}$ faça parte da sua composição.

\section{CONCLUSÕES}

A adubação nitrogenada na cultura da soja, independente da época de aplicação e da cultivar, inibe o número de nódulos, volume dos nódulos e matéria seca dos nódulos e não proporciona aumento do volumer radicular, matéria seca da parte aérea e do sistema radicular. Os cultivares de soja comportam-se morfofisiologicamente de forma diferenciada à época e dose de aplicação de nitrogênio, sendo que o cultivar ST 797 IPRO apresentou maior nodulação e matéria seca das plantas de soja.

\section{AGRADECIMENTOS}

Os autores expressam seus agradecimentos à CAPES (Coordenação de Aperfeiçoamento de Pessoal de Nível Superior) pela concessão de bolsas de PNPD/Capes, e à Universidade Estadual do Mato Grosso do Sul, pelo apoio logístico.

\section{REFERÊNCIAS}

ALMEIDA, J. V. de. A polêmica do uso de nitrogênio em soja. 3. ed. 2015. Disponível em: http://www.doutoresdaterra.com.br/plantas/a-polemica-do-uso-de-nitrogenio-em-soja. Acesso em: 20 abr. 2017.

ARAÚJO, A. S. F.; CARAVALHO, E. M. S. Fixação Biológica de Nitrogênio em Leguminosas. Teresina: UFPI, 2006. p. 1-4.

ARATANI, R. G.; LAZARINI, E.; MARQUES, R. R.; BACKES, C. Adubação nitrogenada em soja na implantação do sistema plantio direto. Bioscience Journal, v. 24, n. 3, p. 31-38, 2008. Disponível em: http://www.seer.ufu.br/index.php/biosciencejournal/ 
article/view/6755/4457. Acesso em: 10 mar. 2017.

BARRANQUEIRO, H. R.; DALCHIAVON, F. C. Aplicação de azoto na cultura da soja. Revista de Ciências Agrárias, v. 40, n. 1, p. 196-204, 2017. Disponível em: http:// www.scielo.mec.pt/pdf/rca/v40n1/v40n1a22.pdf. Acesso em: 14 fev. 2018.

BLANKENSHIP, R. E. Fotossíntese: As Reações Luminosas. In: TAIZ, L.; ZEIGER, E. (ed.). Fisiologia Vegetal. 4. ed. Porto Alegre: Artmed, 2009. p. 147-181.

CASAROLI, D.; FAGAN, E. B.; SIMON, J.; MEDEIROS, S. P.; MANFRON, P. A.; DOURADO NETO, D.; LIER, Q. J. V.; MÜLLER, L.; MARTIN, T. N. Radiação Solar e aspectos fisiológicos na cultura de soja - uma revisão. Revista da FZVA, v. 14, n. 2, p. 102-120, 2007. Disponível em: http://revistaseletronicas.pucrs.br/ojs/index.php/fzva/article/ view/2502/1961. Acesso em: 03 mar. 2017.

CONAB. Companhia Nacional de Abastecimento. Acompanhamento da safra brasileira 2016/2017. Brasília: Conab, 2017. Vol. 4, n. 6 grãos. 175p.

EMBRAPA. Empresa Brasileira de Pesquisa Agropecuária. Tecnologias de produção de soja: Região Central do Brasil. Londrina: Embrapa Soja, 2011.

EMBRAPA. Empresa Brasileira de Pesquisa Agropecuária. Manual de análises químicas de solos, plantas e fertilizantes. Brasília: Embrapa Solos, Embrapa Informática Tecnológica, 2009.

FELISBERTO, G.; BRUZI, A. T.; ZUFFO, A. M.; ZAMBIAZZI, E. V.; SOARES, I. O.; REZENDE, P. M.; BOTELHO, F. B. S. Agronomic performance of RR soybean cultivars using different pre-sowing desiccation periods and distinct post-emergence herbicides. African Journal of Agricultural Research, v. 10, n. 34, p. 3445-3452, 2015. Disponível em: http://academicjournals.org/journal/AJAR/article-full-text-pdf/99F403555151. Acesso em: 18 maio 2017.

HERRIDGE, D. F.; ROSE, I. Breeding fir enhanced nitrogen fixation in crop legumes. Field Crops Research, v. 65, n. 2-3, p. 229-248, 2000. Disponível em: http://www. sciencedirect.com/science/article/pii/S0378429099000891?via\%3Dihub. Acesso em: 15 jun. 2017.

HUNGRIA, M.; VARGAS, M. A. T. Environmental factors affecting $\mathrm{N}_{2}$ fixation in grain 
egumes in the tropics, with an emphasis on Brazil. Field Crops Research, v. 65, p. 151-164, 2000. Disponível em: http://www.sciencedirect.com/science/article/pii/ S0378429099000842?via\%3Dihub. Acesso em: 10 abr. 2017.

HUNGRIA, M.; CAMPO, R. J.; MENDES, I. C. Fixação biológica do nitrogênio na cultura da soja. Londrina: Embrapa Soja, 2001. 48p.

HUNGRIA, M.; FRANCHINI, J. C.; CAMPO, R. J.; CRISPINO, C. C.; MORAES, J. Z.; SIBALDELLI, R. N.; ARIHARA, J. Nitrogen nutrition of soybean in Brazil: contributions of biological $\mathrm{N} 2$ fixation and $\mathrm{N}$ fertilizer to grain yield. Canadian Journal of Plant Science, v. 86, n. 4, p. 927-939, 2006a. Disponível em: http://www.nrcresearchpress.com/doi/pdf/10.4141/P05-098. Acesso em: 22 abr. 2017.

HUNGRIA, M.; CAMPO, R. J.; MENDES, I. C.; GRAHAM, P. H. Contribution of biological nitrogen fixation to the $\mathrm{N}$ nutrition of grain crops in the tropics: the success of soybean (Glycine max (L.) Merr.) in South America. In: SINGH, R. P.; SHANKAR, N.; JAIWAL, P. K. (Ed.). Nitrogen nutrition and sustainable plant productivity. Houston: Studium. p. 43-93, 2006b.

KASCHUK, G.; NOGUEIRA, M. A.; DE LUCA, M. J.; HUNGRIA, M. Response of determinate and indeterminate soybean cultivars to basal and topdressing $\mathrm{N}$ fertilization compared to sole inoculation with Bradyrbizobium. Field Crops Research, v. 195, p. 21-27, 2016. Disponível em: https://www.sciencedirect.com/science/article/pii/ S0378429016301630. Acesso em: 14 fev. 2018.

MORENO, G.; ALBRECHT, A. J. P.; PIEROZAN JUNIOR, C.; PIVETTA, A. T.; TESSELE, A.; LORENZETTI, J. B.; FURTADO, R. C. N. Application of nitrogen fertilizer in high-demand stages of soybean and its effects on yield performance. Australian Journal of Crop Science, v. 12, n. 1, p. 16-21, 2018. Disponível em:

http://www.cropj.com/moreno_12_1_2018_16_21.pdf. Acesso em: 14 fev. 2018.

SAITO, A.; TANABATA, S.; TANABATA, T.; TAJIMA, S.; UENO, M.; ISHIKAWA, S. OHYAMA, T. Effect of nitrate on nodule and root growth of soybean (Glycine max (L.) Merr.). International journal of molecular sciences, v. 15, n. 3, p. 4464-4480, 2014. Disponível em: http://www.mdpi.com/1422-0067/15/3/4464. Acesso em: 22 abr. 2017.

SEDIYAMA, T. Produtividade da soja. Londrina: Mecenas, 2016. 310p. 
SOARES, I. O.; REZENDE, P. M.; BRUZI, A. T.; ZUFFO, A. M.; ZAMBIAZZI, E. V.; FRONZA, V.; TEIXEIRA, C. M. Interaction between soybean cultivars and seed density. American Journal of Plant Science, v. 6, n. 9, p. 1425-1434, 2015. Disponível em: http://file.scirp.org/pdf/AJPS_2015061716011035.pdf. Acesso em: 22 abr. 2017.

ZUFFO, A. M.; REZENDE, P. M.; BRUZI, A. T.; OLIVEIRA, N. T.; SOARES, I. O.; NETO, G. F. G.; CARDILLO, B. E. S.; SILVA, L. O. Co-inoculation of Bradyrbizobium japonicum and Azospirillum brasilense in the soybean crop. Revista de Ciências Agrárias, v. 38, n. 1, p. 87-93, 2015. Disponível em: http://www.scielo.mec.pt/pdf/rca/ v38n1/v38n1a13.pdf. Acesso em: 20 abr. 2017.

ZUFFO, A. M. Aplicações de Azospirillum brasilense na cultura da soja. 2016. 101f. Tese (Doutorado em Agronomia) - Universidade Federal de Lavras, Lavras, 2016.

Recebido em: 25/06/2017

Aceito em: 17/03/2018 